\title{
A Novel DNA extraction protocol from frozen blood of normal individuals and patients who received systemic chemotherapy
}

Hayder O. Hashim ${ }^{1}$, Mohammed Baqur S. Al-Shuhaib ${ }^{2 *}$

${ }^{1}$ Department of Clinical Laboratory Sciences, College of Pharmacy, University of Babylon, Babil 51001, Iraq

ORCID ID0000-0001-8933-0994

${ }^{2}$ Department of Animal Production, College of Agriculture, Al-Qasim Green University, Al-

Qasim 8, Babil 51001, Iraq

ORCID ID0000-0002-6458-2068

\section{DIRECT SUBMISSION}

Keywords; chemotherapy; DNA; extraction; frozen blood; normal; patients

* (Corresponding author) Department of Animal Production, College of Agriculture, Al-Qasim Green University, Al-Qasim-8, Babil 51001, Iraq

E-mail address: mohammed79@agre.uoqasim.edu.iq, baquralhilly_79@yahoo.com

ResearcherID: D-5710-2019, Scopus Author ID: 57196042036, ORCID ID orcid.org/0000-0002-6458-2068 


\begin{abstract}
Herein, we describe a highly efficient, non-complicated, and non-organic procedure to overcome the negative effect of chemotherapeutic drugs on the quality of the extracted DNA by applying several modulations in cell washing, suspension, and lysis of cells treated with these drugs. In this protocol, $500 \mu \mathrm{l}$ were extracted from patients who received systemic sessions of chemotherapy. The validity of this protocol for digestion with restriction endonucleases and both conventional and real-time polymerase chain reaction were tested. This protocol proved obvious

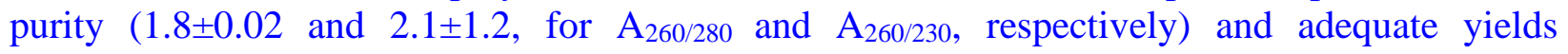
$(10 \pm 2.24) \mu \mathrm{g} / 100 \mathrm{ml}$. The positive results of validation experiments proved the validity of the extracted DNA for downstream applications of molecular biology. In addition to the proven efficiency of this protocol to extract DNA from normal samples, its validity was also confirmed from patients who were exposed to chemotherapy. This entails a novel approach to extract a molecular biology grade DNA without having inhibitors against enzymes used in digestion, amplification, and subsequent sequencing even after the systemic sessions with several doses of chemotherapy.
\end{abstract}

Keywords: DNA extraction, normal, patients, protocol, frozen blood

\title{
Introduction
}

The treatment of cancer has largely been based on the use of chemotherapeutic drugs. Some of these drugs are considered potent DNA damaging agents, which have a long history of employment in cancer chemotherapy [1]. It is well documented that patients receiving chemotherapy have higher levels of DNA damage in blood cells than patients not exposed to chemotherapy [2]. These DNA damaging drugs are not only concerned with the overall instability of gDNA, but it exceeds this limit toward a direct effect on essential biological reactions [3]. Although each chemotherapeutic drug has its own, although often not yet fully understood, mechanism of action [4], there is a general rule that applies to chemotherapeutic drugs that are recognized as DNA damaging agents represented by a straightforward targeting of DNA replication and repair to prevent tumor metastasis [5]. Thus, many chemotherapy drugs exert a negative interference with DNA replisome and cause a direct impairment to DNA replication [6]. Some of these negative effects have been attributed to the presence of purine or pyrimidine nucleoside analogs that directly inhibit the activity of DNA polymerase [7]. The chemotherapy drugs that act as base analogs induce its negative impact by being incorporating into DNA in place of thymine or uracil as in the case of 5-fluorouracil (5-FU). These drugs contain a fluoride atom at the 5-carbon position on the ring to prevents the addition of the next nucleobase on the strand, therefore terminating chain elongation, which may induce apoptosis [8]. So, such drugs may largely hamper interacting enzymes with the extracted DNA and may lead to a possible failure for polymerases involved in the polymerase chain reaction (PCR) and sequencing, site-specific endonucleases involved in restriction fragment length polymorphism (RFLP), or even other downstream clinical applications that require enzymatic intervention. Since of their high efficacy of inhibiting replication in vivo, the ability of chemotherapeutic drugs to prohibit DNA replication in vitro cannot be eliminated. With the progressively prescribed chemical treatments of tumors, the negative impact of these drugs on the extracted DNA is increasingly being confronted. However, in addition to the commonly known methods $[9,10,11]$, series of DNA extraction protocols have recently been devised for DNA extraction 
from blood $[12,13,14]$. Despite the immense progress made in DNA extraction, little attention has been paid to reduce the difficulty of undergoing downstream experiments for DNA samples extracted from patients who are exposed to regular chemotherapeutic sessions. Due to the difficulties surrounding sampling DNA from the whole blood of tumor patients [15], no reliable practical solution for this technical problem has been specifically described. For these reasons, the present study was aimed to design a standard protocol to extract genomic DNA of those patients which can be utilized in the detection and genotyping experiments without being compromised by chemotherapeutic treatment.

\section{Materials and methods}

\section{Ethics}

The present sampling procedure was approved by the research ethics Committee of Babylon Health Directorate (numbered 6086, dated:13/10/2018). The present work was permitted from the research ethics committee in Marjan Teaching Hospital (numbered 13663, dated 22/10/2018).

\section{Abbreviations}

5-FU; 5-fluorouracil, EDTA; ethylene diamine tetra-acetic acid, gDNA; genomic DNA, M; ladder marker, PCR; polymerase chain reaction, qPCR; quantitative PCR, RE; restriction endonuclease, RFLP; restriction fragment length polymorphism, TAE; tris-acetate-EDTA, TBE; tris-borate-EDTA

\section{Reagents/tools}

100 bp ladder marker (BioLabs Inc., cat. no. N3231S), 1 kb ladder marker (BioLabs Inc., cat. no. N3232L), $1.5 \mathrm{ml}$ capacity microfuge tubes, $5 \mathrm{ml}$ capacity Vacutainer tubes, BamHI Restriction enzyme (BioLabs Inc., cat. no. R0136S), Disodium ethylene diamine tetraacetic acid (EDTA; Calbiochem, cat no. 324503), Ethanol absolute (Merck-Millipore, cat. no. 107017), Glacial acetic acid (Merck-Millipore, cat. no. 137130), HinfI Restriction enzyme (BioLabs Inc., cat. no. R0155S), Lyophilized primers (Bioneer), Methanol (Merck-Millipore, cat. no. 107018), Nuclease-free tri-distilled water (BioLabs, cat. no. B1500S), RsaI Restriction enzyme (BioLabs Inc., cat. no. R0167S), Sodium acetate (NaAc; MerckMillipore, cat. no. 106268), Sodium dodecyl sulfate (SDS; Merck-Millipore, cat. no. 817034), Trishydrochloride (Tris-HCl; Merck-Millipore, cat. no. 108219), and RsaI Restriction enzyme (BioLabs Inc., cat. no. R0167S).

\section{Solutions}

Cell suspension buffer: 2 mM EDTA (pH 8.0), Cell lysis buffer: 0.2\% SDS, $20 \mathrm{mM}$ Tris-Cl (pH8), DNA washing buffer: $60 \%$ ethanol in $5 \mathrm{mM}$ Tris- $\mathrm{Cl}$ (pH 8.0), DNA elution buffer: $10 \mathrm{~mm}$ Tris-Cl $\mathrm{pH} 8,1 \mathrm{mM}$ EDTA, Luna ${ }^{\circledR}$ Universal qPCR Master Mix (New England Biolabs, cat. no. \#M3003), PCR premix (Bioneer, cat. no. K-2012), Protein precipitation buffer: 3M sodium acetate, adjusted to $\mathrm{pH} 4.5$ by acetic acid, Tris-acetate-EDTA (TAE) buffer: $40 \mathrm{mM}$ Tris-acetate; $2 \mathrm{mM}$ EDTA (pH 8.3), Tris-borate-EDTA (TBE) buffer: $2 \mathrm{mM}$ of EDTA, $89 \mathrm{mM}$ of Tris-Borate (pH 8.3), Washing buffer: $10 \%$ methanol and $18 \mathrm{~mm}$ Tris- $\mathrm{Cl}(\mathrm{pH} 7.5)$ 


\section{Equipment}

Agarose gel electrophoresis unit (CleaverScinetific, cat. no. MSCHOICE7), Centrifuge equipped with a fixed angle rotor of FA-24x2 (Eppendorf, cat. no. 5405000514), Gel documentation imaging system (JUNYI Electrophoresis, cat. no. JY04S-3C), Gradient PCR thermocycler (Eppendorf, cat. no. 6331000017), Micropipettes (Eppendorf, P-200, and P-1000), nanodrop spectrophotometer (Biodrop, part no. 80-3006-51), Rotating mixer of 48x1.5/2.0ml capacity (Benchmark Scientific, cat. no. R5010), RotorGene Q Real-Time PCR System (Qiagen, cat. no. 9001620), Water bath (Thermo-Scientific, cat. no. TSSWB15).

\section{Blood sampling}

The total number of blood samples that taken from patients were 207, in which patients who suffered from several grades of several types of tumors $(54,48,31,20,19,16,11$ and 8 samples of bladder, colorectal, breast, ovarian, non-small cell lung, pancreatic, cervical and hepatocellular carcinomas, respectively) were included in this study. All those patients were being exposed to systemic chemotherapeutic sessions which were included short (32-94 min) and long (245-638 min) infusions with 5-FU (uridine - thymidine analog). From each involved patient, only $500 \mu \mathrm{l}$ was specified for this study, which was routinely provided by personnel of Marjan Teaching Hospital in Babylon. Written Informed consent was obtained from each included patient who was involved in this study. All blood samples were frozen under $-20^{\circ} \mathrm{C}$ until being processed for DNA extraction.

\section{DNA extraction protocol}

1. Cells washing; the frozen blood sample that was placed in a vacutainer tube was thawed at room temperature and mixed gently. Then, only $500 \mu \mathrm{l}$ of the blood was transferred to an Eppendorf tube of $1.5 \mathrm{ml}$ capacity. Up to $1 \mathrm{ml}$ of washing buffer was added to the blood sample, mixed, and incubated at ambient temperature for $10 \mathrm{~min}$, or $5 \mathrm{~min}$ in a rotating mixer. The mixture was centrifuged at $10000 \mathrm{~g}$ for $2 \mathrm{~min}$. After discarding the supernatant, $1 \mathrm{ml}$ of washing buffer was added again, and the tube was inverted several times to wash the pellet then centrifuged at the same speed for 10 seconds. The supernatant was discarded and the pellet was gently suspended with $1 \mathrm{ml}$ of washing buffer by forth and back pipetting with a wide orifice tip, and centrifuged for $1 \mathrm{~min}$. The previous step was repeated once, twice, or once a yellowish-white precipitate of leukocytes appears).

2. Cells lysis. The pellet was suspended with $200 \mu$ l of cell suspension buffer and mixed several times to remove cellular aggregations. Then, $200 \mu \mathrm{l}$ of cell lysis buffer was added to the generated homogenate, mixed, and then left at room temperature for 5 min (Supplementary material).

3. Proteins precipitation. Proteins were denatured by mixing of cellular lysate with $100 \mu l$ of protein precipitation buffer for vortexed for $20 \mathrm{sec}$. Afterward, the suspension was centrifuged at $10000 \mathrm{~g}$ for $10 \mathrm{~min}$. The supernatant containing DNA was transferred to a new $1.5 \mathrm{ml}$ centrifuge tube.

4. DNA precipitation and washing. Up to $1 \mathrm{ml}$ of absolute ethanol was added to the supernatant and inverted until optimally DNA threads appeared. Subsequently, centrifugation at $10000 \mathrm{~g}$ for $1 \mathrm{~min}$ was performed. The supernatant was discarded and $1 \mathrm{ml}$ of DNA washing buffer 
was added and mixed well with the pelleted DNA and left for 1 min to re-suspend DNA. The suspension was centrifuged at $10000 \mathrm{~g}$ for $1 \mathrm{~min}$ and the supernatant was discarded.

5. DNA recovery. After dehydration at room temperature, the pelleted DNA was mixed with 100 $\mu l$ of DNA elution buffer. The mixture was incubated for $15 \mathrm{~min}$ at $65^{\circ} \mathrm{C}$ in a water bath to speed up recovery.

\section{Qualitative and quantitative evaluation of the isolated DNA}

The concentration and purity of the isolated DNA were analyzed by a Nanodrop spectrophotometer. DNA concentration measurements were recorded as $\mu \mathrm{g} / \mathrm{ml}$, while DNA purity was taken from the ratio obtained from the A260/280 absorbance formula. A graphical representation of spectrophotometric parameters was generated using Microsoft Excel boxplot.

\section{Digestion with Restriction endonucleases (RE)}

The extracted DNA was exposed to digestion with several REs to confirm the absence of any possible inhibitor for the biological activity of these enzymes. Randomly selected samples of gDNA were digested with three different REs, BamHI (5'...GGATCC...3'), HinfI (5'...GANTC...3'), and RsaI. (5'...GTAC...3'), according to instruction manuals recommended by manufacturers' suppliers (BioLabs Inc., 240 County Road, USA). Briefly, $1 \mu \mathrm{g}$ of gDNA was diluted with $18 \mu \mathrm{l}$ of distilled water. Then, $2 \mu \mathrm{l}$ of $10 \mathrm{X}$ RE-mix and 10U of each selected RE were added. The mixture was incubated overnight at $37^{\circ} \mathrm{C}$, and analyzed by standard $1.5 \%(\mathrm{w} / \mathrm{v})$ agarose gel electrophoresis in TBE buffer.

\section{Electrophoresis}

The integrity of the gDNA was assessed by a direct running of a series of gradually increasing concentrations of gDNA in a standard $0.8 \%(\mathrm{w} / \mathrm{v})$ agarose gel electrophoresis unit in TAE buffer and photographed by gel documentation imaging system. The quality was also considered in the gel as the integral gDNA migrate as a relatively well-defined band while degraded gDNA takes a smeared migration pattern [16].

\section{Conventional PCR}

DNA amplification was performed to ensure the validity of the extracted DNA to act as a competent template for PCR reaction and to confirm the absence of any possible inhibitor for Taq DNA polymerase activity. Ten pairs of specific primers were designed by the primer BLAST server [17] to (Table 1).

Table 1. The designed primers of the PTEN, LEPR, Kras, and ATM genes by NCBI primer BLAST tool.

\begin{tabular}{|c|c|c|c|c|c|}
\hline No. & $\begin{array}{l}\text { Primers' } \\
\text { code }\end{array}$ & Sequence (5'-3') & $\begin{array}{l}\text { Length } \\
\text { (bp) }\end{array}$ & $\begin{array}{l}\text { Annealing } \\
\text { temp. }\end{array}$ & NCBI accession number \\
\hline \multirow[t]{2}{*}{1} & PTEN-F & TGCTGCAGTCCATTGAGCATA & 658 bp & $60.1^{\circ} \mathrm{C}$ & NC_000010.11 \\
\hline & PTEN-R & GCTGTGGTGGGTTATGGTCTT & & & \\
\hline \multirow[t]{2}{*}{2} & $L E P R-\mathrm{F}$ & GCAGCTCTGAAAGGGGTTGTA & $103 \mathrm{bp}$ & $61.1^{\circ} \mathrm{C}$ & NC_000001.11 \\
\hline & $L E P R-\mathrm{R}$ & CGGTAATCAGCTGTGGGACT & & & \\
\hline \multirow[t]{2}{*}{3} & Kras-F & АCTCСТCTTGACCTGCTGTG & $107 \mathrm{bp}$ & $59.8^{\circ} \mathrm{C}$ & NC_000012.12 \\
\hline & Kras- $\mathrm{R}$ & AATCCAGACTGTGTTTCTCCCTT & & & \\
\hline \multirow[t]{2}{*}{4} & $A T M-\mathrm{F}$ & GCCATTCTATGGTAGCCCCC & 345 bp & $61.9^{\circ} \mathrm{C}$ & NC_000011.10 \\
\hline & $A T M-\mathrm{R}$ & TGCAAAAACTCACCTCAAGCA & & & \\
\hline
\end{tabular}


A total reaction volume of $20 \mu \mathrm{l}$ containing a lyophilized PCR premix, $0.7 \mu 1$ of $10 \mu \mathrm{M}$ of both forward and reverse primers, $1 \mu \mathrm{l}$ of the extracted DNA template, and $17.6 \mu 1$ nuclease-free tri-distilled water, was used for PCR amplification. The optimum annealing temperatures for the designed primers were empirically determined using a gradient thermal cycler. The PCR program was set by initial denaturation at $94^{\circ} \mathrm{C}$ for $4 \mathrm{~min}$, followed by 30 cycles of denaturation at $94^{\circ} \mathrm{C}$ for 30 seconds, annealing temperature ranged from 59 to $61.3^{\circ} \mathrm{C}$ for 30 seconds, and elongation at $72^{\circ} \mathrm{C}$ for 30 seconds, and was concluded with a final extension at $72^{\circ} \mathrm{C}$ for 5 min. Subsequently, PCR products were assessed by $1.5 \%$ agarose gel electrophoresis. PCR products were exposed to sequencing reactions from both termini according to instructions of the sequencing laboratories (Macrogen, Geumchen, Seoul, Korea).

\section{Real-time PCR}

More confirmation of the validity of the extracted DNA was conducted using real-time PCR to provide a further indication for the presence of amplifiable DNA in extracts of blood samples. One set of primer pairs was designed to partially amplify $167 \mathrm{bp}$ of GTA gene; forward primer 5'-TATTTCTGCATGGGCCAGGG-3', and primer reverse 5'ACTCGGAGAAACAAAGTGCCT-3'. Real-time PCR amplifications were conducted using a Rotor-Gene Q Real-Time PCR System. A universal Luna ${ }^{\circledR}$ qPCR Master Mix was employed for the amplification of different extracted DNA concentrations (1000-1 ng). All samples were run in duplicates, and the $\mathrm{Ct}$ values, amplification efficiency, y-intercept, slope, dynamic range, and other parameters were calculated according to instructions of manufacturers (Rotor-Gene Q software version 2.1).

\section{Results and discussion}

The present protocol of DNA extraction was validated by a series of conventional experiments that were commonly used in molecular biology. The conducted spectrophotometric results showed high yield and purity of the DNA extracted by this protocol. The average yield of isolated DNA was estimated at $10 \pm 2.24 \mu \mathrm{g}$ per $100 \mathrm{ml}$. Furthermore, the absorbance ratio scored highly acceptable levels as they were valued 1.78 into 1.81 , and $2.0-2.21$ for $\mathrm{A}_{260 / 280}$ and A260/230 respectively, which signified low levels of contamination. However, relatively higher amounts of DNA were obtained from normal samples, which was simply attributed to the absence of any exposure to DNA impairment agents of 5-FU found in the received chemotherapeutic sessions.

Table 2. Yield and purity of the genomic DNA extracted from frozen blood obtained from normal donors and patients who are exposed to chemotherapy. Values are expressed as means \pm SD.

\begin{tabular}{llll}
\hline Frozen blood sample & DNA yield $(\mu \mathrm{g} / 100 \mathrm{ml})$ & $\mathrm{A}_{260 / 280}$ & $\mathrm{~A}_{260 / 230}$ \\
\hline Normal & $13 \pm 4.22$ & $1.79 \pm 0.04$ & $2.1 \pm 0.8$ \\
Patient & $10 \pm 2.24$ & $1.80 \pm 0.02$ & $2.1 \pm 1.2$ \\
\hline
\end{tabular}

The electrophoretic experiments performed showed clear integrity of the extracted DNA samples, which indicated no smear or other contaminating particles even when very high concentrations of DNA were being analyzed (Figure 1, A). Most importantly, the readability of this DNA for digestion by restriction enzymes was tested (Figure 1, B). Clear activity for the 
utilized REs was detected and DNA samples were easily degraded by these enzymes. Another layer of confirmation came from conventional PCR, in which specific bands were observed in all amplified loci (Figure 1, C - F). More verifications were obtained from qPCR experiments, in which the extracted DNA by our protocol showed high purity and inhibitors-free amplification reaction. Results showed successful amplification of low and high concentrations of DNA (1ng $1 \mu \mathrm{g})$, respectively. An accepted dynamic range for the extracted DNA was achieved with calculated efficiency and $r$ values 0.91 and 0.99 respectively (Figure $1, \mathrm{G}-\mathrm{H}$ ).

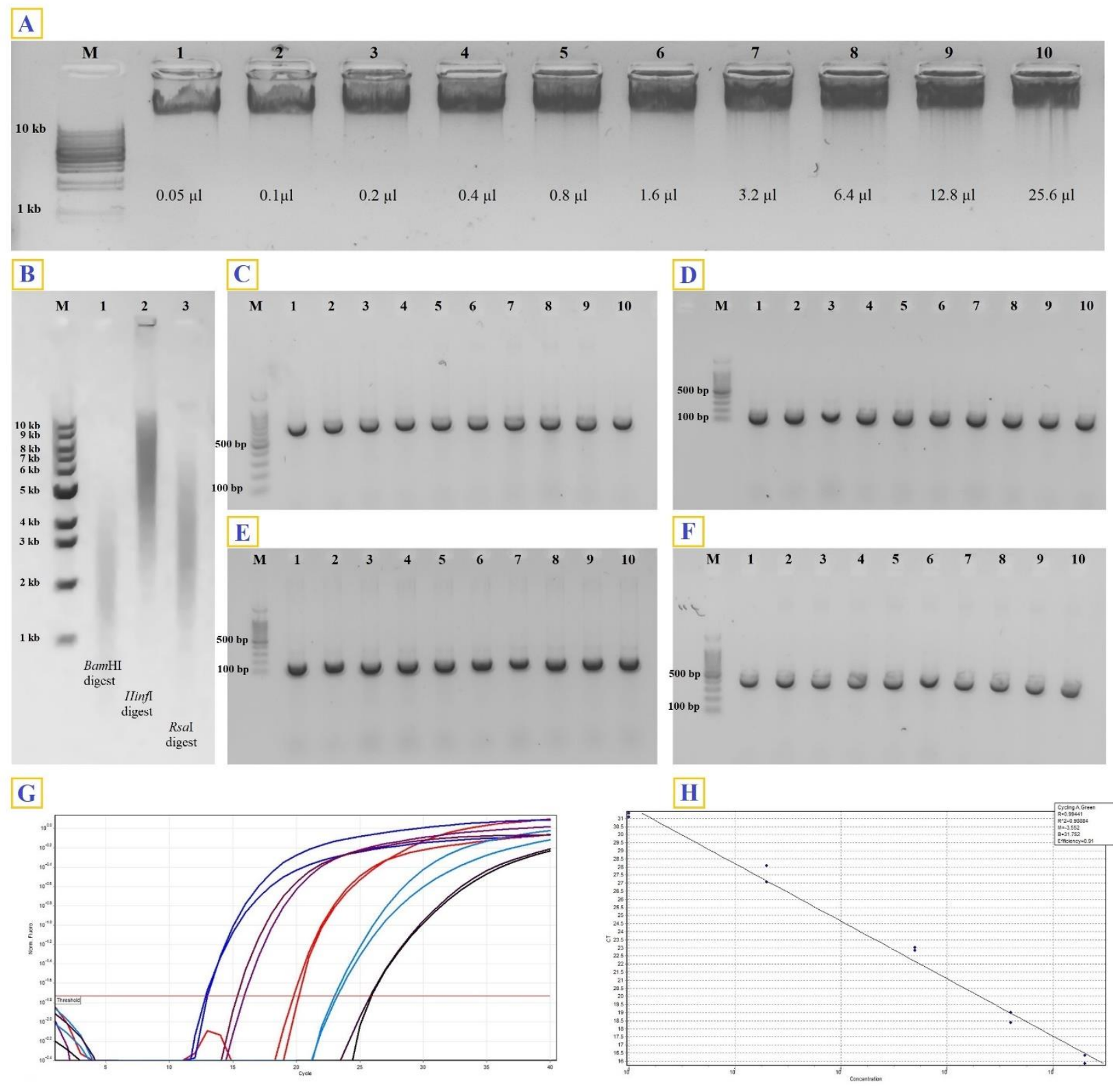

Fig. 1. Validation of the DNA extraction protocol using several techniques. A) $0.8 \%$ agarose gel electrophoresis of various gradual concentrations of genomic DNA. B) DNA digestion with restriction endonucleases. C - F) agarose gel electrophoresis of $658 \mathrm{bp}, 103 \mathrm{bp}, 107 \mathrm{bp}$, and $345 \mathrm{bp}$ PCR products, respectively. $\mathrm{G}-\mathrm{H}$ ) real-time PCR for 167 bp PCR products. The symbol M refers to the ladder marker. 
These successive experiments demonstrated the absence of any significant inhibitor for the enzymes used in DNA digestion, conventional PCR, and quantitative PCR reactions and indicated that the isolated DNA was in excellent quality. To provide further validation of this protocol, PCR products were exposed to many standard sequencing reactions, which showed clear electrocardiographs, with obvious alignments with the referring sequences.

Several types of chemotherapeutic drugs have fluorescent compounds that inhibit the activity of many enzymes used in molecular diagnostics. One of these commonly used drugs is 5-FU, which is an effective pyrimidine analog that is being used to treat several types of malignancies [18]. The uridine - thymidine analog, a synthetic form of 5-FU, differs from deoxycytidine by the addition of two fluorine atoms at the $2^{\prime}$-position of the sugar. The triphosphate form of 5-FU functions as a substrate for DNA polymerases involved in DNA synthesis [19, 20]. After 5-FU is incorporated as a pyrimidine analog, DNA synthesis is terminated. Therefore, 5-FU has an inevitable inhibitive role against interactive enzymes in molecular genetics. This role has been ascribed to the presence of this chemotherapeutic drug which has eliminated any competency of the extracted DNA for downstream standard genotyping experiments. We have made several trials to investigate the eligibility of such DNA extracted by several commonly used methods [10, 11, 21, 22]. However, extremely low reproducibility of these DNA samples was found after being evaluated by several downstream enzymatic-based genetic experiments. Therefore, the currently described protocol was designed to solve issues surrounding the incompetency of these DNA samples for interactive enzymes used in molecular biology. Though considerable variations regarding DNA concentrations in cancer patients were reported [23], our protocol has proven superiority after being several experiments. According to our results, the persisting inhibiting effects of the chemotherapeutic agents were eliminated in our protocol. This evidence may be attributed to the substantial modifications applied in cell washing, in which the majority of these counterfeiting agents were eradicated. After a series of efforts, we have managed to use $10 \%$ methanol in cell washing instead of other available solutions to solve this issue. The utilization of methanol induces a reduction in polarity and surface tension in such a way cellular chemotherapeutic agents would be eliminated alongside other cellular sediments [24]. Furthermore, several trials were performed to make this protocol more familiar. The chemical composition described in this method was designed to include commonly available chemicals to provide further simplicity for routine investigations without being compromised by greater labor input by having more steps and chemicals in removing 5-FU. This piece of evidence - in turn - is very beneficial in terms of reducing costs and efforts without scarifying DNA in these samples. Add to that, the non-organic / non-enzymatic steps have also proven more feasibility of our protocol as it does not require the hazardous inclusion of toxic organic solvents [13], or the extended incubation with proteinase K [25]. However, the utilization of this protocol is not restrained with these chemotherapeutic cases, it can be used to extract DNA with a considerable efficiency for downstream molecular biology experiments. The DNA quality obtained by our protocol is highly acceptable as it is found to be around 1.8, while the DNA yield is sufficient for performing at least 50 PCR experiments. After validating this protocol by a series of experiments, a confirmation to obtain the highest purity grade needed in RFLP, PCR, and qPCR experiments was provided. In addition to the application of this protocol for DNA extraction in the essential experiments, it is confirmed to be competent for sequencing protocols. This evidence was based on many sequencing reactions conducted on PCR products, which showed clear chromatograms with optimal baselines, which implies no possible contamination for sequencing reactions. The 
observed distinct results for many validating experiments showed a non-controversial efficacy of this method. According to many validations conducted for this method, we suggest using it in the DNA isolation from patients who are exposed to systemic chemotherapeutic sessions. Therefore, it can be stated that this is the first DNA extraction protocol specially designed to remove all fluorescent inhibitors found in the DNA extracted from patients undergoing chemotherapy with high efficiency.

In conclusion, all experimental validations performed have confirmed the competency of this protocol to eliminate the fluorescence agents found in the drugs used to treat tumorigenic patients. The chemical compositions of the DNA extraction protocol have eradicated the negative interaction of 5-FU against endonucleases and polymerases used in our validation experiments. In addition to the advent feasibility of the present protocol for normal samples, we strongly recommend it in DNA extraction from patients who are intensively exposed to chemotherapy.

\section{Conflict of interest}

Non.

\section{Authors' contribution}

$\mathrm{HOH}$ conceived the main idea of the protocol, designed experiments, performed laboratory work, MBSA analyzed the data and wrote the manuscript. Both authors revised and approved the final manuscript.

\section{Acknowledgments}

This study was partially supported by Alfadhil Scientific training company, Babil, Iraq (019-3).

\section{References}

1. K. Cheung-Ong, G. Giaever, C. Nislow, DNA-damaging agents in cancer chemotherapy: serendipity and chemical biology. Chem. Biol. 2013 (20) 648-59, doi:http://dx.doi.org/10.1016/j.chembiol.2013.04.007

2. A.S. Kværner, J. Minaguchi, N. El Yamani, C. Henriksen, H. Ræder, I. Paur, H.B. Henriksen, G. Wiedswang, S. Smeland, R. Blomhoff, A.R. Collins, S.K. Bøhn, DNA damage in blood cells in relation to chemotherapy and nutritional status in colorectal cancer patients-A pilot study. DNA Repair 63 (2018) 16-24, doi:http://dx.doi.org/10.1016/j.dnarep.2018.01.005

3. H. Kitao, M. Iimori, Y. Kataoka, T. Wakasa, E. Tokunaga, DNA replication stress and cancer chemotherapy. Cancer Sci. 109 (2018) 264-271, doi:http://dx.doi.org/10.1111/cas.13455

4. A. Lin, C.J. Giuliano, A. Palladino, K.M. John, C. Abramowicz, M.L. Yuan, E.L. Sausville, D.A. Lukow, L. Liu, A.R. Chait, Z.C. Galluzzo, J.M. Sheltzer, Off-target toxicity is a common mechanism of action of cancer drugs undergoing clinical trials. Sci. Transl. Med. 11 (2019) eaaw8412, doi:http://dx.doi.org/10.1126/scitranslmed.aaw8412

5. J. A. Nickoloff, D. Jones, S.-H. Lee, E. A. Williamson, R. Hromas, Drugging the Cancers Addicted to DNA Repair. J. Natl. Cancer Inst. 109 (2017) 1-13, doi:http://dx.doi.org/10.1093/jnci/djx059

6. H. Maeda, M. Khatami, Analyses of repeated failures in cancer therapy for solid tumors: poor tumorselective drug delivery, low therapeutic efficacy and unsustainable costs. Clin. Transl. Med. 7 (2018) 11, doi:http://dx.doi.org/10.1186/s40169-018-0185-6

7. A.J. Berdis, Inhibiting DNA Polymerases as a Therapeutic Intervention against Cancer. Front. Mol. Biosci. 4 (2017) 78, doi:http://dx.doi.org/10.3389/fmolb.2017.00078 
8. W.B. Parker, Y.C. Cheng, Metabolism and mechanism of action of 5-fluorouracil. Pharmacol. Ther. 48 (1990) 381-395, doi:http://dx.doi.org/10.1016/0163-7258(90)90056-8

9. A.J. Jeffreys, D.B. Morton, DNA fingerprints of dogs and cats. Anim. Genet. 18 (1987) 1-15, doi:http://dx.doi.org/10.1111/j.1365-2052.1987.tb00739.x

10. D.K. Lahiri, S. Bye, J.I. Nurnberger, M.E. Hodes, M. Crisp, A non-organic and non-enzymatic extraction method gives higher yields of genomic DNA from whole-blood samples than do nine other methods tested. J. Biochem. Biophys. Methods 25 (1992) 193-205, doi:http://dx.doi.org/10.1016/0165-022x(92)90014-2

11. J. Sambrook, D.W. Russell, Molecular cloning: a Laboratory Manual. 3rd ed. Vol. 1, 2, and 3. New York, USA: Cold Spring Harbor Laboratory Press, 2001.

12. M.B.S. Al-Shuhaib, A Universal, rapid, and inexpensive method for genomic DNA isolation from the whole blood of mammals and birds. J. Genet. 96 (2017) 171-176, doi:http://dx.doi.org/10.1007/s12041-017-0750-6

13. P. Guha, A. Das, S. Dutta, T.K. Chaudhuri, A rapid and efficient DNA extraction protocol from fresh and frozen human blood samples. J. Clin. Lab. Anal. 32 (2018) e22181, doi:http://dx.doi.org/10.1002/jcla.22181

14. M. Margulis, A. Danielli, Rapid and Sensitive Detection of Repetitive Nucleic Acid Sequences Using Magnetically Modulated Biosensors. ACS Omega 4 (2019) 11749-11755. doi:http://dx.doi.org/10.1021/acsomega.9b01071

15. V. Haselmann, P. Ahmad-Nejad, W.J. Geilenkeuser, A. Duha, M. Gabor, R. Eichner, S. Patton, M. Neumaier, Results of the first external quality assessment scheme (EQA) for isolation and analysis of circulating tumour DNA (ctDNA). Clin. Chem. Lab. Med. 26 (2017) 220-228, doi:http://dx.doi.org/10.1515/cclm-2017-0283

16. M.B.S. Al-Shuhaib, A minimum requirements method to isolate large quantities of highly purified DNA from one drop of poultry blood. J. Genet. 97 (2018) e87-e94, doi:http://dx.doi.org/10.1007/s12041-018-0983-z

17. J. Ye, G. Coulouris, I. Zaretskaya, I. Cutcutache, S. Rozen, T. Madden, Primer-BLAST: A tool to design target-specific primers for polymerase chain reaction. BMC Bioinformatics 13 (2012) 134, doi:http://dx.doi.org/10.1186/1471-2105-13-134

18. F. Eckel, G. Schneider, R.M. Schmid, Pancreatic cancer: a review of recent advances. Expert Opin. Invest. Drugs 2006 (15) 1395-1410, doi:http://dx.doi.org/10.1517/13543784.15.11.1395

19. A.T.Hulme, S.L., Price, D.A. Tocher, A New Polymorph of 5-Fluorouracil Found Following Computational Crystal Structure Predictions. J. Am. Chem. Soc. 127 (2005) 1116-1117, doi:http://dx.doi.org/10.1021/ja044336a

20. N. Zhang Y. Yin, S.J. Xu, W.S. Chen. 5-Fluorouracil: mechanisms of resistance and reversal strategies. Molecules.13(2008) 1551-1569, doi:http://dx.doi.org/10.3390/molecules13081551

21. C. G. Albariño, V. Romanowski, Phenol extraction revisited: a rapid method for the isolation and preservation of human genomic DNA from whole blood. Mol. Cell. Prob. 8 (1994) 423-427, doi: http://dx.doi.org/10.1006/mcpr.1994.1060

22. P.R. Subbarayan, M. Sarkar, B. Ardalan, Isolation of genomic DNA from human whole blood. Biotechniques, 6 (2002) 1231-1234, doi:http://dx.doi.org/10.2144/02336bm10

23. R.E. Board, V.S. Williams, L. Knight, J. Shaw, A. Greystoke, M. Ranson, C. Dive, F.H. Blackhall, A. Hughes, Isolation and extraction of circulating tumor DNA from patients with small cell lung cancer. Ann. NY Acad. Sci. 1137 (2008) 98-107, doi:http://dx.doi.org/10.1196/annals.1448.020.

24. Y.F. Yano, Correlation between surface and bulk structures of alcohol-water mixtures, J. Colloid Interf. Sci. 284 (2005) 255-259, doi:http://dx.doi.org/10.1016/j.jcis.2004.09.059

25. W. Qamar, M.R. Khan, A. Arafah, Optimization of conditions to extract high quality DNA for PCR analysis from whole blood using SDS-proteinase K method. S. J. Biol. Scie. 24 (2017) 1465-1469, doi:https://doi.org/10.1016/j.sjbs.2016.09.016 


\section{Supplementary Material}
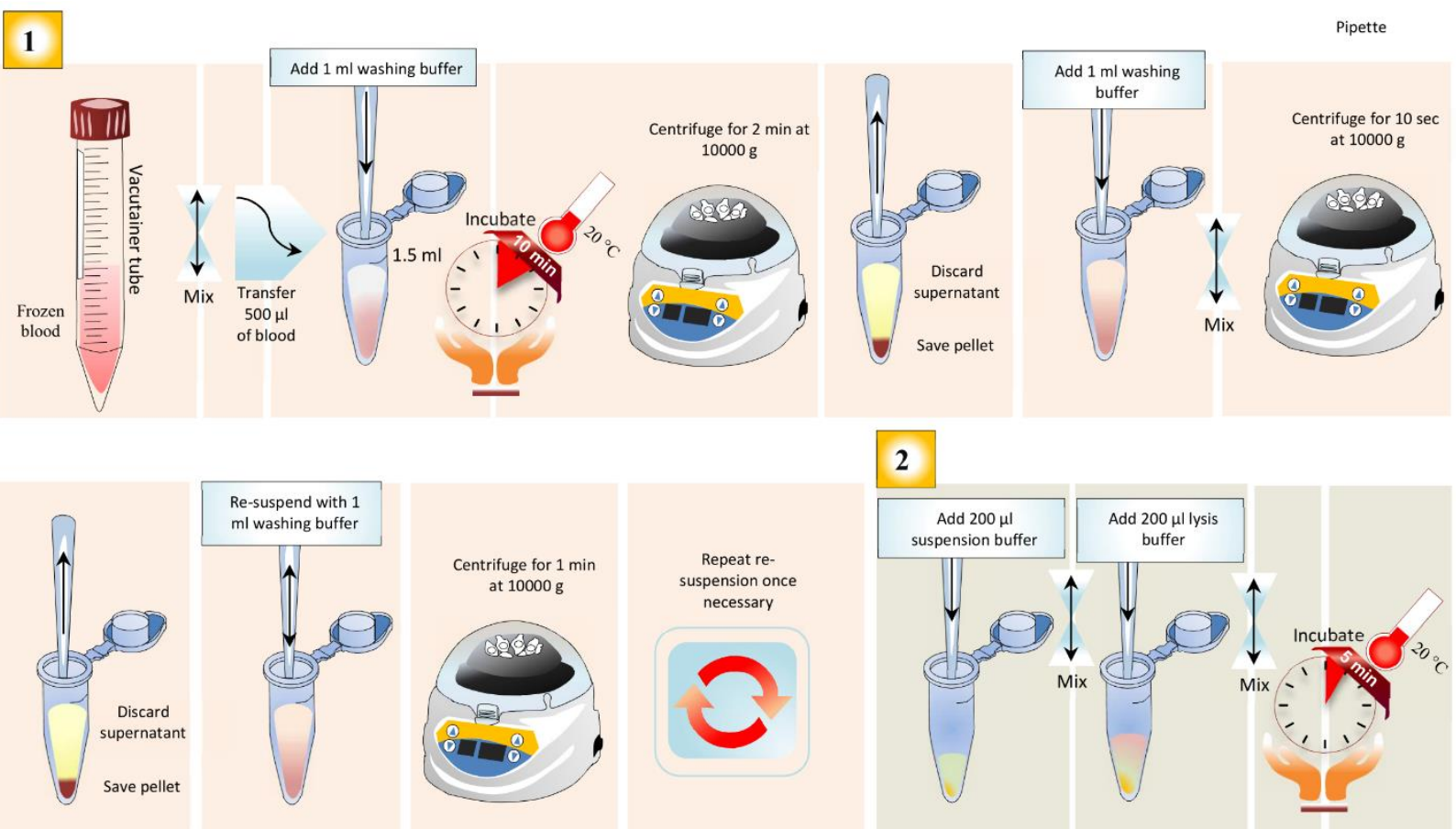

\section{2}
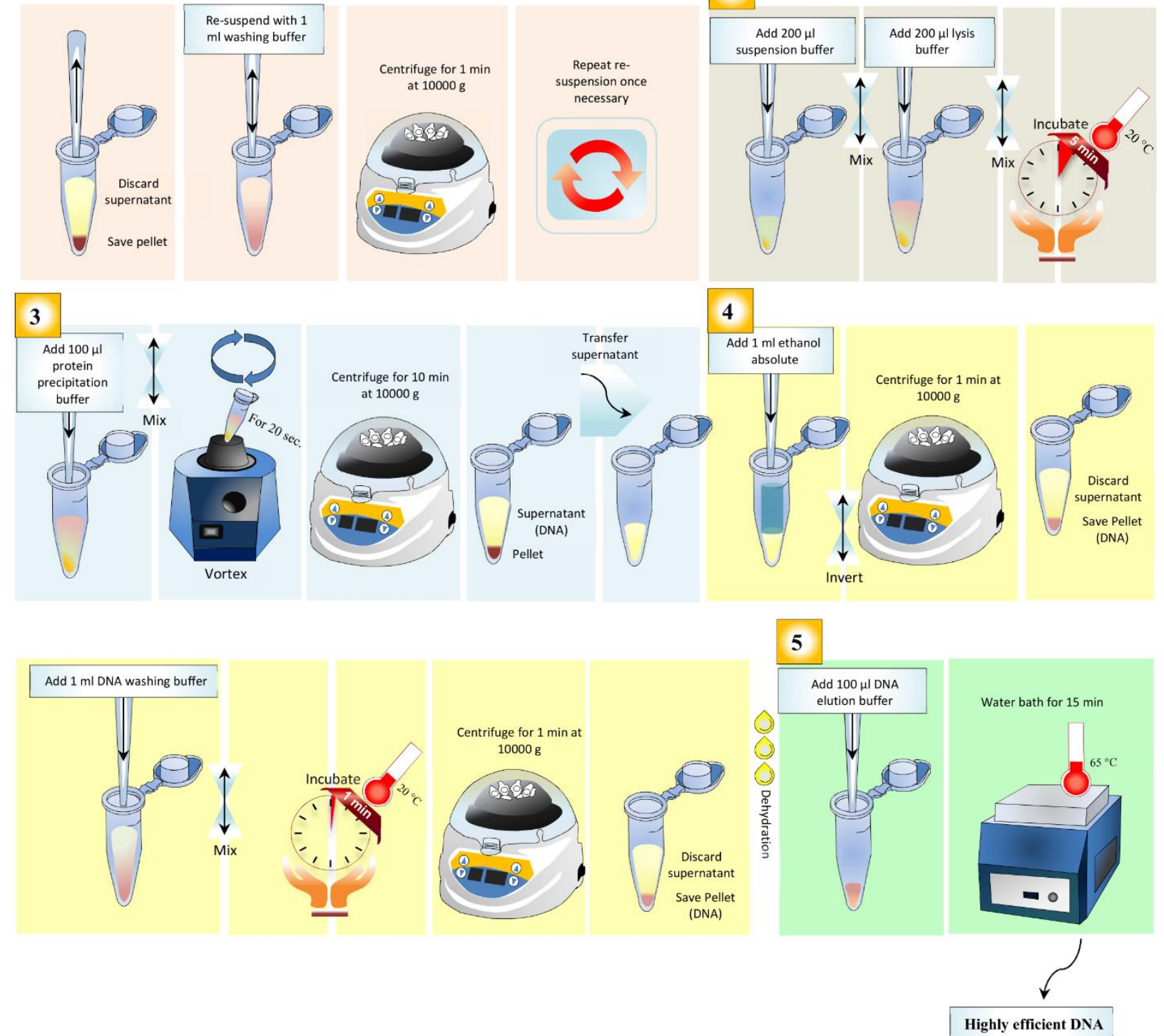

Supplementary Material. A graphical abstract for the described novel DNA extraction steps of this study. 